\title{
Optimal management of fatigue in patients with systemic lupus erythematosus: a systematic review
}

This article was published in the following Dove Press journal:

Therapeutics and Clinical Risk Management

I October 2014

Number of times this article has been viewed

\author{
Hon K Yuen' \\ Melissa A Cunningham² \\ 'Department of Occupational \\ Therapy, School of Health Professions, \\ University of Alabama at Birmingham, \\ Birmingham, AL, ${ }^{2}$ Division of \\ Rheumatology and Immunology, \\ Department of Medicine, Medical \\ University of South Carolina, SC, USA
}

Abstract: Among the host of distressing pathophysiological and psychosocial symptoms, fatigue is the most prevalent complaint in patients with systemic lupus erythematosus (SLE). This review is to update the current findings on non-pharmacological, pharmacological, and modality strategies to manage fatigue in patients with SLE and to provide some recommendations on optimal management of fatigue based on the best available evidence. We performed a systematic literature search of the PubMed and Scopus databases to identify publications on fatigue management in patients with SLE. Based on the studies reported in the literature, we identified nine intervention strategies that have the potential to alleviate fatigue in patients with SLE. Of the nine strategies, aerobic exercise and belimumab seem to have the strongest evidence of treatment efficacy. $\mathrm{N}$-acetylcysteine and ultraviolet-A1 phototherapy demonstrated low-tomoderate levels of evidence. Psychosocial interventions, dietary manipulation (low calorie or glycemic index diet) aiming for weight loss, vitamin D supplementation, and acupuncture all had weak evidence. Dehydroepiandrosterone is not recommended due to a lack of evidence for its efficacy. In addition to taking treatment efficacy and side effects into consideration, clinicians should consider factors such as cost of treatment, commitments, and burden to the patient when selecting fatigue management strategies for patients with SLE. Any comorbidities, such as psychological distress, chronic pain, sleep disturbance, obesity, or hypovitaminosis D, associated with fatigue should be addressed.

Keywords: health-related quality of life, vitality, systemic lupus erythematosus, clinical effectiveness, rheumatology

\section{Introduction}

Systemic lupus erythematosus (SLE) is a chronic, multisystem, inflammatory, autoimmune connective tissue disorder. It is characterized by production of pathogenic autoantibodies and dysregulated immune responses by B-cells, T-cells, dendritic cells, and other immune cells, resulting in numerous clinical and serological manifestations. ${ }^{1}$ A broad array of clinical presentations ranging from rash, oral ulcers, and arthralgias to life-threatening internal organ involvement such as lupus nephritis is common. ${ }^{2}$ The course of SLE is extremely variable and is characterized by intermittent and unpredictable remissions and exacerbations (ie, flares) during which the immune system attacks various organs. ${ }^{3}$ With recurrent flares (approximately $65 \%$ of patients per year), ${ }^{3}$ SLE can lead to progressive disability. The cause of SLE is unknown, but is likely to be an interaction of genetic, environmental, and hormonal factors. ${ }^{1}$ SLE affects mostly women, with an incidence about nine times higher than in men, and also has a higher prevalence in non-Caucasian populations. ${ }^{4}$
Correspondence: Hon K Yuen Department of Occupational Therapy, School of Health Professions, University of Alabama at Birmingham, 1720 Second Avenue South, Birmingham, AL 35294, USA

Tel +l 2059346301

Fax + I 2059757787

Email yuen@uab.edu 
Due to earlier diagnosis and better treatment options to control the disease and its complications, the 5-year survival of patients with SLE has exceeded $90 \%$ in most centers. ${ }^{5}$ With a significant improvement in survival in this population, attention has additionally been directed toward improving health-related quality of life. Among the host of distressing pathophysiological and psychosocial symptoms, fatigue is the most prevalent complaint in approximately $50 \%-90 \%$ of patients with SLE, ${ }^{6}$ with more than $50 \%$ of patients rating fatigue as the most debilitating symptom they experience. ${ }^{7}$ Fatigue manifests as an overwhelming sense of extraordinary tiredness or exhaustion that is not completely relieved by rest or sleep. ${ }^{8}$

In most cases the cause of fatigue is unknown. A number of factors associated with SLE-related fatigue have been reported, including pathochronobiological factors (sleep disturbance, physical inactivity), pathopsychosocial factors (anxiety, depression), chronic pain (fibromyalgia), obesity, and lack of perceived social support. ${ }^{9-14}$ Some studies have shown an association between disease activity (ie, cytokine and autoantibody levels) and fatigue, ${ }^{9,10,15,16}$ while others have reported that fatigue is not associated with any disease markers. ${ }^{17,18}$ Furthermore, fatigue was also reported in patients without clinical or laboratory evidence of active disease. $^{7}$

For many patients with SLE, fatigue disrupts normal daily functioning, decreases the ability to concentrate, and affects work, leisure, and social activities, leading to diminished quality of life, ${ }^{6,19}$ a high prevalence of work disability, ${ }^{20,21}$ and higher health care utilization. ${ }^{22}$ At the same time, more than $80 \%$ of patients with SLE have reported that fatigue is not adequately addressed in their health care management plan..$^{23,24}$

The aim of this review is to update the current findings on several non-pharmacological, pharmacological, and modality strategies to manage fatigue in patients with SLE and to provide some recommendations on optimal fatigue management based on the best available evidence.

\section{Materials and methods \\ Literature search strategy}

This systematic review was conducted according to the guidelines of the Preferred Reporting Items for Systematic Reviews and Meta-Analyses. ${ }^{25}$ The process began with the first author (HKY) performing a systematic electronic literature search of the PubMed and Scopus databases from their inception (1966 and 1996, respectively) to May 2014. Queries to identify potentially relevant publications on fatigue management in patients with SLE were based on Boolean combinations of the following search terms: ((lupus [tiab] OR SLE [tiab]) AND (fatigue [tiab] OR vitality [tiab] OR SF-36 [tiab] OR quality of life [tiab])). We also identified appropriate articles that were cited in review papers related to fatigue and lupus.

\section{Study eligibility criteria}

We limited this review to publications that were in the English language, with full text available, the majority of patients diagnosed with SLE, and adults (ie, 18+ years), although children could constitute a minority of the participants in a study. Only intervention and observational studies reporting a fatigue or vitality measure as one of the primary or secondary outcomes were included. Studies were excluded if they were case reports, dissertations, editorials, commentaries, or review articles, or if they employed primarily qualitative research methods.

\section{Data extraction}

The first author (HKY) screened the titles and abstracts of all the articles that had been retrieved to determine if they met the eligibility criteria, and appraised the methodological quality and evidence of each selected study. The second author (MC) subsequently reviewed the accuracy and quality of the appraisal. Any disagreements were discussed until consensus was reached. The flow diagram in Figure 1 describes the process used to select articles for this study, and the results of this literature search.

\section{Results}

Based on the studies reported in the literature, we identified nine intervention strategies that have the potential to alleviate fatigue in patients with SLE. These strategies were psychosocial intervention, exercise, diet manipulation, vitamin D supplementation, N-acetylcysteine (NAC), dehydroepiandrosterone (DHEA), belimumab, ultraviolet-A1 (UVA-1) phototherapy, and acupuncture. The results of our critical review on the clinical efficacy evidence of each strategy to improve fatigue or vitality are summarized as follows.

\section{Psychosocial intervention}

Approximately $40 \%$ of patients who have SLE remain distressed over time, and since there is a significant association between distress and fatigue, these patients may benefit from psychosocial interventions. ${ }^{26}$ Psychosocial interventions for fatigue management in patients with SLE included cognitive behavioral therapy, ${ }^{27,28}$ psychoeducation, ${ }^{29,30}$ counseling, ${ }^{30,31}$ 


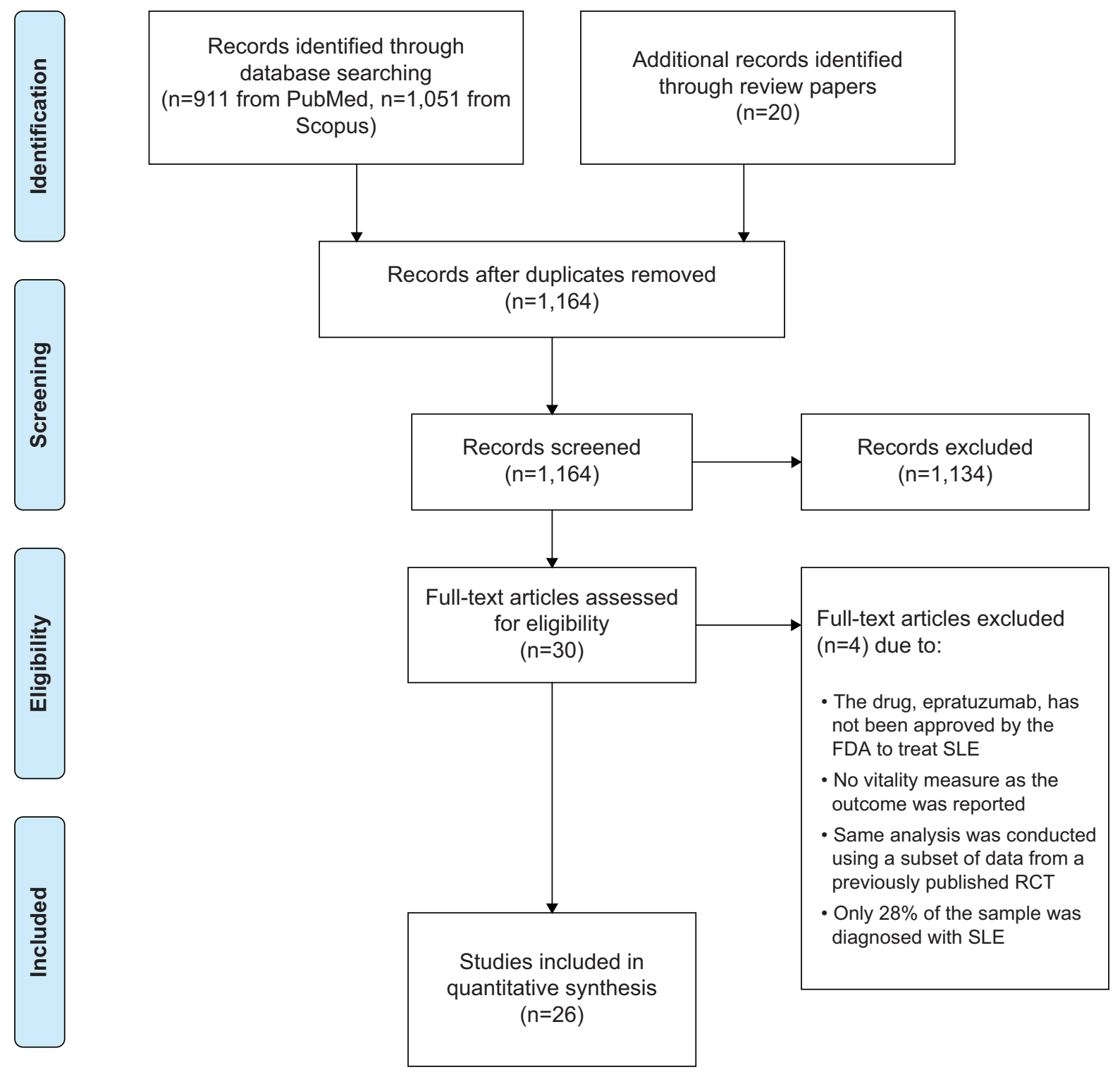

Figure I Flow diagram of the selection process and study search results.

Abbreviations: FDA, US Food and Drug Administration; SLE, systemic lupus erythematosus; RCT, randomized controlled trial.

psychotherapy, ${ }^{29,32}$ and biofeedback, ${ }^{28}$ with the aim of reducing interference by the disease with activities of daily living, improving interpersonal relationships, social support, selfefficacy, and coping skills for stress management. ${ }^{33}$ These interventions focused primarily on reducing psychological distress (ie, stress, anxiety and depressive symptoms), fatigue, and pain, and consisted of skills training in relaxation, pain control, problem-solving, coping, social interaction (eg, interpersonal relationship, assertiveness), and cognitive restructuring.

Of the seven psychosocial intervention studies identified, two were non-randomized controlled trials (non-RCTs, one being a single group pretest-posttest design study ${ }^{29}$ and one being a non-equivalent control group pretest-posttest design study), ${ }^{33}$ and five were RCTs. ${ }^{27,28,30-32}$ The two non-RCTs demonstrated a decrease in fatigue or an improvement in vitality. ${ }^{29,33}$ Of the five RCTs, only one demonstrated a reduction in fatigue. ${ }^{30}$ The other four trials showed that psychosocial interventions resulted in either no significant decrease in fatigue when compared with standard usual care ${ }^{27,28,32}$ or were equally effective in reducing fatigue when compared with placebo (ie, symptom monitoring only). 28,31

The RCT that demonstrated a decrease in fatigue compared a psychoeducational intervention with an attention placebo control. ${ }^{30}$ Patients and their partners assigned to the intervention group $(n=64)$ received a 1-hour session with a 
nurse educator and subsequent monthly telephone counseling for 6 months, whereas participants $(n=58)$ in the attention placebo group received a 45-minute video presentation about lupus and monthly telephone monitoring. The authors used a four-item visual analog scale (VAS) to assess levels of patient fatigue when performing various daily activities. ${ }^{34}$ Rating on the scale ranged from 0 (no fatigue) to 10 (extreme fatigue). There was no significant difference in fatigue scores between the intervention and placebo groups at 6 months (ie, immediate post-telephone counseling); however, a significant difference in fatigue scores was observed between the intervention and placebo groups at 12 months ( 6 months without intervention for both groups), with the intervention group reporting less fatigue. ${ }^{30}$ This phenomenon may suggest that the findings were not reliable and simply reflected sample attrition.

Overall, there was only a 0.7 -point improvement in fatigue score from baseline to 12 months in the intervention group. ${ }^{30}$ This amount of reduction did not reach the minimal clinically important difference (MCID) for the fatigue VAS, which was estimated to be 1.3 points. ${ }^{35}$ Furthermore, as revealed in a previous meta-analysis study, ${ }^{36}$ pooled analysis of the effects of psychosocial interventions on fatigue with another $\mathrm{RCT}^{28}$ indicated that no significant difference in fatigue scores between the intervention and control groups was observed.

Based on the available evidence, psychosocial interventions seem effective in reducing psychological distress and pain, ${ }^{36}$ and in improving problem-focused coping ability, selfefficacy, and perceived social support. ${ }^{33}$ However, evidence to support psychosocial interventions in alleviating fatigue in patients with SLE was very weak. Furthermore, no immediate or sustained (12-month follow-up) effects of psychosocial intervention on physical function, mental health, and SLE disease activity were observed. ${ }^{36}$

\section{Exercise}

Since physical inactivity was found to be significantly associated with fatigue in patients with SLE, 9,12 exercise is a logical strategy to alleviate fatigue. Studies of exercise for patients with SLE used primarily aerobic exercise, in which the exercise was conducted either at a specific site (ie, supervised) or at home (ie, unsupervised) with weekly telephone monitoring. Typically, exercise was performed three times per week for 30-50 minutes, achieving an intensity of $60 \%-80 \%$ of the participant's maximum heart rate, and the duration of the study ranged from 8 to 12 weeks. The primary aims of the exercise programs were to increase exercise tolerance, aerobic capacity, and perceived physical function, and to reduce fatigue.

Of the seven exercise studies identified, three were non-RCTs (one being a non-equivalent control group pretest-posttest design study ${ }^{37}$ and two being single group pretest-posttest design studies), ${ }^{38,39}$ and four were RCTs. ${ }^{34,40-42}$ Three of the RCTs ${ }^{34,40,42}$ and the non-equivalent control group study $^{37}$ demonstrated that exercise significantly reduced fatigue when compared with the controls. The RCT that did not show a significant difference in fatigue was likely due to inadequate statistical power as the sample size of each group was only $5 .{ }^{41}$ For this trial, ${ }^{41}$ following the 2 -month supervised exercise program, the magnitude of fatigue reduction, as measured by the nine-item Fatigue Severity Scale (FSS), ${ }^{43}$ exceeded the threshold (ie, 0.6 points) of the MCID for the FSS. ${ }^{35,41}$ Both single group studies showed significant improvement in fatigue after exercise. ${ }^{38,39}$ In addition, exercise has been shown to be safe and does not aggravate SLE disease activity. ${ }^{34,38,40-42}$

The findings of these studies highlighted the role of exercise in reducing fatigue in patients with SLE; however, few studies evaluated long-term exercise adherence in patients with SLE or the sustained effect of exercise on reducing fatigue in this population. Therefore, large-scale RCTs with long-term follow-up are needed to support this conclusion.

In addition, there are issues related to difficulty measuring fatigue and interpreting findings in these studies. Most exercise studies included several measures for fatigue, but often only one fatigue measure was found to be significantly different between the exercise and control groups. ${ }^{34,37,40,42}$ In addition, among these studies, no one particular fatigue measure consistently showed a significant difference between groups. For example, there were two exercise studies of similar research design conducted by the same group of researchers; $;^{34,40}$ both used two fatigue measures, ie, the seven-item fatigue subscale of the Profile of Mood States ${ }^{44}$ and a four-item VAS for fatigue. ${ }^{34}$ One study found that the fatigue subscale of Profile of Mood States scores, but not the VAS fatigue scores, were significantly different between the groups, while the other study found the opposite. ${ }^{34,40}$

Willingness to participate in an exercise program or to continue exercise regularly after the study program ended was a significant problem. In one home-based exercise study, patients received a free Wii console and Wii Fit balance board, mitigating the need for travel to a fitness center for exercise, and the accrual rate was only $43 \% .{ }^{39}$ In another exercise study, the researchers recruited 93 patients to 
participate, but mentioned that 31 eligible patients declined to participate due to lack of time. ${ }^{42}$ In addition, about one fifth $(18 \%)$ of the participants assigned to the exercise group did not attend any supervised exercise sessions. ${ }^{42}$ This appears to indicate a lack of enthusiasm on the part of patients with SLE to participate in exercise training. Finally, less than a quarter $(24 \%)$ of the participants in that study continued to exercise regularly at the 3 -month follow-up. ${ }^{42}$

\section{Manipulation of diet}

Between $40 \%$ and $50 \%$ of adults with SLE are classified as obese. ${ }^{14,45-47}$ Obese patients with SLE are more likely to experience higher levels of fatigue. ${ }^{13,14}$ Davies et al conducted a randomized comparative trial to explore the safety and benefits of special diets with regard to weight loss and fatigue reduction in patients with SLE. ${ }^{48}$ They compared a low glycemic index (GI) diet $(n=11)$ versus a low calorie $\operatorname{diet}(\mathrm{n}=12)$ in 23 patients for 6 weeks. Fatigue was measured using the FSS. ${ }^{43}$ The results indicated that both diets were equally effective in reducing fatigue and helping patients to lose weight. Fatigue reduction was reported by seven of the eleven participants in the low GI diet group, and four of the 12 in the low calorie diet group. The fatigue score was reduced by 0.5 points in the low GI diet group, and 0.3 points in the low calorie diet group. However, the amount of reduction did not reach the MCID of 0.6 points for the FSS. ${ }^{35}$ Both diets were well tolerated, with mild adverse effects (headache, constipation, increased bowel frequency, bloating), and SLE disease activity remained unchanged.

\section{Vitamin D supplementation}

Sunlight avoidance, use of sunscreen, renal insufficiency, and drugs (such as chloroquine and prednisone) prescribed to treat the symptoms of SLE interfere with vitamin D metabolism and put patients with SLE at risk for vitamin D deficiency. ${ }^{49}$ In fact, hypovitaminosis $\mathrm{D}$ is common in patients with SLE. ${ }^{49}$

Evidence regarding the association between vitamin D deficiency and fatigue is inconsistent. In an open-label observational study, 60 patients with SLE took dietary vitamin $\mathrm{D}_{3}$ supplements (400-1,200 IU per day) for 2 years, by which time significant improvement in fatigue scores, as measured by a 10 -point VAS for fatigue, was observed. ${ }^{50}$ There was a 0.8-point improvement in fatigue score, but this did not reach the MCID of 1.3 points for the fatigue VAS. ${ }^{35}$ Due to the lack of a control group and the unmasked nature of this open-label study, strong bias related to self-reported fatigue levels was unavoidable.
In that study, a significant association between serum $25(\mathrm{OH}) \mathrm{D}$ and fatigue levels at 2-year follow-up was also observed. ${ }^{50}$ In contrast, the majority of cross-sectional studies did not find any significant relationship between vitamin D and fatigue levels. ${ }^{51-54}$ Participants in these cross-sectional studies did not know their serum 25(OH)D level or the purpose of the investigation. ${ }^{51-54}$ Although few in number, the findings of these studies do not support vitamin D supplementation as having a significant direct effect on improving fatigue in patients with SLE.

\section{$\mathrm{N}$-acetylcysteine}

$\mathrm{NAC}$, an amino acid precursor of glutathione, serves as an inhibitor of autoimmune inflammatory processes. ${ }^{55}$ The data suggest that patients with SLE have low levels of glutathione. ${ }^{56}$ Lai et al conducted a double-blind, placebocontrolled, randomized trial to explore the safety and benefits of orally formulated NAC in patients with SLE. ${ }^{57}$ Thirty-six patients received either placebo $(n=9)$ or one of three daily doses (1.2 g, $2.4 \mathrm{~g}$, or $4.8 \mathrm{~g}$ ) of NAC for 3 months $(\mathrm{n}=9$ in each dose group). After 1-3 months, significant improvement was achieved with the two higher NAC doses, ie, $2.4 \mathrm{~g}$ /day and $4.8 \mathrm{~g} /$ day, in terms of anti-DNA, disease activity, and fatigue as measured by the Fatigue Assessment Scale ${ }^{58}$ when compared with placebo. In addition, for the $2.4 \mathrm{~g}$ /day group, the amount of fatigue reduction exceeded the MCID of 4 points for the Fatigue Assessment Scale. ${ }^{59}$

Regardless of the mean baseline score, participants who received NAC $2.4 \mathrm{~g} /$ day or $4.8 \mathrm{~g} /$ day, or placebo all rated their fatigue level reduced to about 24 at 3 months. However, the mean \pm standard deviation score on the Fatigue Assessment Scale in a random sample from an adult Dutch population was 19.2 $\pm 6.5 .^{58}$ According to this pioneer work, a $2.4 \mathrm{~g} /$ day dose of NAC is effective for reducing fatigue but may not be potent enough to reduce fatigue in patients with SLE to a level that is comparable with that in the general population. The $2.4 \mathrm{~g}$ /day dose was tolerated by all participants, but the $4.8 \mathrm{~g}$ /day dose was less well tolerated, with one third of the participants reporting headache, heartburn, nausea, and vomiting. ${ }^{57}$

\section{Dehydroepiandrosterone}

DHEA is a naturally occurring mild androgen with immunomodulatory properties. ${ }^{60}$ The data suggest that patients with SLE have lower mean serum DHEA levels, ${ }^{61}$ and lower levels of DHEA might relate to increased fatigue. ${ }^{62}$ Beneficial health effects of DHEA supplementation in patients with SLE include reducing disease activity and improving global 
well-being and functioning. ${ }^{63-66}$ However, several doubleblind, randomized, placebo-controlled trials have assessed the effect of orally formulated DHEA (200 mg per day) on fatigue specifically, and concluded that DHEA has either no effect on reducing fatigue or the same effect as placebo. ${ }^{66-69}$ Possible side effects in DHEA users include acne, hirsutism, weight gain, and menstrual changes, making this therapy less attractive to female lupus patients. ${ }^{60}$

\section{Belimumab}

Belimumab is a fully humanized monoclonal antibody that binds to the soluble form of B-lymphocyte stimulator protein and inhibits its biological activity. ${ }^{70}$ B-lymphocyte stimulator protein, also known as B-cell activating factor, is an immunomodulatory cytokine that promotes B-cell proliferation and survival. ${ }^{71}$ B-lymphocyte stimulator protein levels are high in patients with SLE and correlate with changes in disease activity. ${ }^{72}$

Two large multisite international collaboration trials assessed the efficacy of belimumab in patients with active SLE. ${ }^{73,74}$ They compared two doses of belimumab (1 and $10 \mathrm{mg} / \mathrm{kg}$ ) with placebo over 1 year. The pooled analysis of data from these two randomized, double-blind, placebocontrolled clinical trials in 1,684 patients showed that both doses of belimumab administered intravenously once a month significantly reduced disease activity and corticosteroid use, and improved scores in the four-item vitality scale of the Medical Outcome Study 36-item Short-Form Health Survey (SF-36) and Functional Assessment of Chronic Illness Therapy Fatigue (FACIT-Fatigue) scale at week 52 when compared with placebo. ${ }^{75}$ Mean score improvements in both FACIT-Fatigue and SF-36 vitality scales exceeded the MCIDs of their respective scales. ${ }^{75}$ The SF-36 vitality scale score at week 52 was comparable with age-matched and sex-matched US norms. ${ }^{75}$ In fact, significant differences in FACIT-Fatigue scale scores were observed between belimumab and placebo beginning at week $8 .{ }^{76}$

In addition, extending the first phase of these two trials, 296 patients who completed the 52-week, double-blind treatment continued to receive monthly belimumab $10 \mathrm{mg} / \mathrm{kg}$ for 4 years in an open-label study. ${ }^{77}$ The results indicated that the number of patients experiencing fatigue after 4 years of belimumab therapy decreased by four-fold (to 7.3\%) compared with placebo or baseline. ${ }^{77}$

Belimumab is effective for reducing fatigue in patients with active SLE and without severe nephritis or central nervous system involvement. ${ }^{78}$ Adverse effects in belimumab users include headache, insomnia, arthralgia, gastrointestinal complaints (nausea, diarrhea), infection (upper respiratory tract, urinary tract infections), cellulitis, psychiatric disorders (anxiety, depression with increased suicidal ideation), and transient ischemic attack. ${ }^{77,79}$

\section{Ultraviolet-A I phototherapy}

With the discovery of the immunosuppressive properties of long-wavelength ultraviolet radiation (ie, a UVA-1 range of $340-400 \mathrm{~nm}$ ), this modality serves as a potential adjuvant therapy for SLE. ${ }^{80}$ Polderman et al conducted a randomized, double-blind, placebo-controlled crossover trial to evaluate the safety and benefits of UVA-1 phototherapy. ${ }^{81}$ In two consecutive 12-week periods, eleven patients with mild to moderate SLE received low-dose $\left(6 \mathrm{~J} / \mathrm{cm}^{2}\right)$ whole-body UVA-1 phototherapy and a placebo light treatment five times per week for the first 3 weeks, or vice versa. Patients who received the UVA-1 phototherapy showed a significant improvement in the SF-36 vitality scale score compared with the same patients who received placebo. A 16-point increase in vitality score after UVA-1 phototherapy was observed. ${ }^{81}$ Score improvement exceeded the threshold (ie, 3-5 points) of the MCID for the SF-36 vitality scale. ${ }^{35,82}$ However, none of the other seven subscales or total SF-36 scores showed a significant difference following UVA-1 phototherapy when compared with placebo. Based on the $P$-value (0.03) provided, the comparison between the vitality score following UVA-1 phototherapy and placebo would not be statistically significant, had corrections for chance been made.

UVA-1 phototherapy did not achieve a significant improvement in disease activity when compared with placebo; ${ }^{81}$ however, a subsequent study conducted by the same group of researchers reported that UVA-1 (when doubling the intensity) was more effective than placebo in reducing SLE disease activity. ${ }^{83}$ No signs of photosensitivity or other adverse events were reported at the lower dose; ${ }^{81}$ however, as might be expected, two of 12 patients in the subsequent study had transient skin reactions (ie, erythema). ${ }^{83}$ Serious adverse effects of UVA-1 may include photocarcinogenesis, phototoxicity, and induction of photodermatoses. ${ }^{84}$ Contraindications to UVA-1 phototherapy are disorders of photosensitivity, long-term use of immunosuppressants and photosensitizing agents, history of skin cancer, or receiving radiation therapy. ${ }^{84}$ It appears that UVA-1 phototherapy may be effective in reducing fatigue in patients with SLE, although larger-scale RCTs with long-term follow-up would be needed to confirm the previous findings and ensure its safety in lupus patients, which is uncertain. 


\section{Acupuncture}

A systematic review on the effectiveness of acupuncture in reducing fatigue in patients with chronic fatigue syndrome indicated that about $92 \%$ of patients pooled from 13 studies who received acupuncture alone or augmented with moxibustion reported effectiveness in fatigue reduction. ${ }^{85} \mathrm{Greco}$ et al conducted a modified double-blind RCT to explore the safety and benefits of acupuncture in reducing fatigue and pain in patients with SLE. ${ }^{86}$ They compared standardized acupuncture with minimal needling (sham) and usual care in 24 patients (eight in each group) during ten sessions over approximately 5 weeks. ${ }^{86}$ Fatigue was measured using the FSS $^{43}$ and SF-36 vitality scale. ${ }^{87}$ The results indicated that acupuncture and minimal needling were significantly superior to usual care in reducing fatigue. However, acupuncture and minimal needling were equally effective. The mean improvement scores on FSS and SF-36 vitality scale were 0.35 points and 1.6 points, respectively. However, the amount of reduction did not reach the MCID of 0.6 points for the FSS or 3-5 points for the SF-36 vitality scale. ${ }^{35,82}$ Only one of eight (13\%) participants in the acupuncture group achieved clinical improvement in fatigue (vitality). Approximately $40 \%$ of participants in the acupuncture group reported an improvement in pain score, but no improvement in disease activity was observed.

Only transient adverse events, including local bruising, pain during needle insertion, dizziness, and lightheadedness were reported in the acupuncture and minimal needling groups ${ }^{86}$ Acupuncture is not recommended for SLE patients with advanced visceral organ involvement. ${ }^{88}$

\section{Discussion}

Since fatigue management is part of the overall treatment of patients with SLE, selection of fatigue management strategies may often be dictated by the treatment that targets control of SLE disease activity. Strategies for fatigue management should be selected using those that are least invasive and with the fewest side effects. In addition to taking treatment efficacy and side effects into consideration, clinicians should consider factors such as cost of treatment, commitment, and burden to the patient when selecting fatigue management strategies with SLE (see Table 1). These important factors need to be assessed when evaluating any strategies for fatigue management in patients with SLE using well-designed, large-scale RCTs with long-term follow-up in order to provide robust clinical evidence.

Even though evidence of the efficacy of psychosocial interventions for reducing fatigue in patients with SLE is weak, such interventions are effective in reducing psychological distress and pain in this population, ${ }^{36}$ and should be integrated into fatigue management. Based on the existing evidence, optimal management of fatigue for patients with SLE should start with lifestyle changes, which include aerobic exercise and dietary manipulation with the aims of increasing physical activity and weight control, respectively. Although clinicians should always encourage healthy choices by their patients, there are, undeniably, many barriers to modifying lifestyle and thus these changes are often difficult for patients with SLE to implement and sustain.

Since vitamin D supplementation for SLE patients with hypovitaminosis D is associated with significant improvement in disease activity ${ }^{89}$ clinicians frequently prescribe vitamin D supplementation as an adjuvant therapy for patients with SLE who are also diagnosed with low levels of serum $25(\mathrm{OH}) \mathrm{D}$. Therefore, hypovitaminosis $\mathrm{D}$-associated fatigue should be managed with vitamin D supplements.

Even though evidence for efficacy of the NAC supplement in reducing SLE disease activity and fatigue is still in the early phase of clinical trials, its use in fatigue management for patients with SLE is encouraging. Given that NAC supplements at $2.4 \mathrm{~g} /$ day have minimal side effects, and the cost of this supplement is affordable, it may be included in fatigue management.

Belimumab is a prescription medication that has been approved by the US Food and Drug Administration to treat SLE, and has been shown to reduce fatigue (ie, to increase vitality). However, side effects and the high cost of this medication are two factors that need to be considered when prescribing belimumab for fatigue management.

The use of UVA-1 phototherapy to manage fatigue for patients with SLE is somewhat encouraging, but the data are limited and safety concerns remain, as it may exacerbate SLE. The long-term efficacy and side effects of UVA-1 are unknown, so caution should be exercised in prescribing this modality to treat SLE. Furthermore, not all rheumatology clinics have the appropriate apparatus and personnel to provide this service.

For SLE patients with pain as a contributing factor associated with fatigue who do not want to rely on medications to control pain, acupuncture is an option to manage fatigue. Evidence to support its efficacy in fatigue reduction for patients with SLE is weak, and patients must be unafraid of acupuncture needling and be able to afford to pay out-of-pocket as it is not widely covered by insurance plans for treating SLE. Pain can also be simultaneously managed using meditation or biofeedback (part of psychosocial intervention). 
Table I Considerations of various intervention strategies on fatigue management in patients with SLE

\begin{tabular}{|c|c|c|c|c|c|}
\hline Intervention & Efficacy & Evidence & $\begin{array}{l}\text { Sample } \\
\text { size }\end{array}$ & $\begin{array}{l}\text { Treatment } \\
\text { duration }\end{array}$ & $\begin{array}{l}\text { Dosage or frequency } \\
\text { of administration }\end{array}$ \\
\hline Psychosocial & $\begin{array}{l}\text { Weak, not reaching MCID } \\
\text { threshold }\end{array}$ & $\begin{array}{l}\text { Only one RCT } \\
\text { showed delayed } \\
\text { positive effect }{ }^{30}\end{array}$ & $\begin{array}{l}\mathrm{TG}=64 \\
\mathrm{PG}=58\end{array}$ & 6 months & $\begin{array}{l}\text { A single I-hour in-person } \\
\text { session and } 6 \text { monthly } \\
\text { telephone counseling } \\
\text { sessions }\end{array}$ \\
\hline Exercise & Moderate-strong & Four RCTs $\mathrm{s}^{34,40-42}$ & $n=160$ & $\geq 8$ weeks & $\begin{array}{l}\text { Three times/week, } \\
30 \text { minutes each }\end{array}$ \\
\hline Dietary manipulation & $\begin{array}{l}\text { Weak, not reaching MCID } \\
\text { threshold }\end{array}$ & $\begin{array}{l}\text { Only one small } \\
\text { pilot } \mathrm{RCT}^{48}\end{array}$ & $\begin{array}{l}\mathrm{TG}_{1}=11 \\
\mathrm{TG}_{2}=12\end{array}$ & 6 weeks & $\begin{array}{l}\text { For low Gl diet: limited } \\
\text { to } 45 \mathrm{~g} / \text { day carbohydrate } \\
\text { For low calorie diet: } \\
\text { limited to } 2,000 \mathrm{kcal} / \mathrm{day}\end{array}$ \\
\hline $\begin{array}{l}\text { Vitamin D } \\
\text { supplementation }\end{array}$ & $\begin{array}{l}\text { Very weak, not reaching } \\
\text { MCID threshold }\end{array}$ & $\begin{array}{l}\text { No RCT } \\
\text { available, } \\
\text { one observational } \\
\text { study }\end{array}$ & $\mathrm{n}=60$ & $\geq 7$ months & 400-I,200 IU daily, orally \\
\hline $\mathrm{N}$-acetylcysteine & Moderate & $\begin{array}{l}\text { Only one small } \\
\text { pilot } \mathrm{RCT}^{57}\end{array}$ & $\begin{array}{l}\mathrm{TG}_{1}=9 \\
\mathrm{TG}_{2}=9 \\
\mathrm{TG}_{3}=9 \\
\mathrm{PG}=9\end{array}$ & 3 months & $1.2 \mathrm{~g}$, twice daily, orally \\
\hline DHEA & Not effective & Four RCTs s6-69 & $\begin{array}{l}\mathrm{TG}=366 \\
\mathrm{PG}=303\end{array}$ & 12 months & $200 \mathrm{mg}$ daily, orally \\
\hline Belimumab & $\begin{array}{l}\text { Very strong, reduces } \\
\text { fatigue to a level that is } \\
\text { comparable with the norm }\end{array}$ & $\begin{array}{l}\text { Two multisite } \\
\text { Phase III RCTs }{ }^{75,76}\end{array}$ & $\begin{array}{l}\mathrm{TG}_{1}=559 \\
\mathrm{TG}_{2}=563 \\
\mathrm{PG}=562\end{array}$ & $\geq 8$ weeks & $\begin{array}{l}10 \mathrm{mg} / \mathrm{kg} \text {, monthly, } \\
\text { intravenously }\end{array}$ \\
\hline $\begin{array}{l}\text { Ultraviolet-AI } \\
\text { phototherapy }\end{array}$ & Weak-moderate & $\begin{array}{l}\text { Only one small } \\
\text { pilot } \mathrm{RCT}^{81}\end{array}$ & $\mathrm{n}=\mathrm{II}$ & 12 weeks & $\begin{array}{l}3 \text { weeks, } 5 \text { days/week } \\
\text { (or } 200 \text { second } \\
\text { exposure time); total } \\
\text { body irradiation of } \\
\text { UVA-I }(340-400 \mathrm{~nm} \text { ) } \\
\text { with } 6 \mathrm{~J} / \mathrm{cm}^{2}\end{array}$ \\
\hline Acupuncture & $\begin{array}{l}\text { Weak, not reaching MCID } \\
\text { threshold, only one of eight } \\
\text { patients showed clinical } \\
\text { improvement }\end{array}$ & $\begin{array}{l}\text { Only one small } \\
\text { pilot } \mathrm{RCT}^{86}\end{array}$ & $\begin{array}{l}\mathrm{TG}=8 \\
\text { Sham }=8 \\
\mathrm{CG}=8\end{array}$ & 5 weeks & 10 sessions \\
\hline
\end{tabular}

Abbreviations: GI, glycemic index; FDA, US Food and Drug Administration; MCID, minimal clinical important difference; OTC, over the counter; RCT, randomized controlled trial; UVA-I, ultraviolet-AI; CG, control group; PG, placebo group; TG, treatment group; SLE, systemic lupus erythematosus; DHEA, dehydroepiandrosterone.

\section{Limitations}

Given that this review was limited to papers published in the English language, with full text available, it is possible that we may have missed some important studies written in languages other than English, not indexed in these two databases (PubMed and Scopus), or as part of reporting bias. To reduce the probability of excluding appropriate studies relevant to this review, we used the tracking citations function of Scopus to locate additional appropriate articles that cited our selected studies. We did not include or evaluate a study of epratuzumab, an experimental drug administered at a dose of $360 \mathrm{mg} / \mathrm{m}^{2}$, which has been shown to improve the SF-36 vitality scale score at week 48 , exceeding age-matched and sex-matched US normative values, ${ }^{90}$ as epratuzumab has not yet been approved by the US Food and Drug Administration to treat SLE. We also did not include another RCT on the benefit of expressive writing on reduction of fatigue because only about one quarter of patients in that study had SLE (54/75 [72\%] of the participants had rheumatoid arthritis) and no disease group stratum was formed before randomization, ${ }^{91}$ so it is not possible to accurately interpret the beneficial findings of expressive writing and attribute that to SLE participants only.

\section{Conclusion}

Of the nine strategies for fatigue management in patients with SLE reviewed in this study, aerobic exercise and belimumab seem to have the strongest evidence for treatment efficacy. NAC and UVA-1 phototherapy demonstrated 


\begin{tabular}{|c|c|c|c|c|}
\hline Cost & Common side effects & $\begin{array}{l}\text { Acceptability to } \\
\text { patients }\end{array}$ & $\begin{array}{l}\text { Required } \\
\text { lifestyle change }\end{array}$ & Availability \\
\hline $\begin{array}{l}\text { Not normally covered by } \\
\text { health insurance if just for } \\
\text { fatigue management }\end{array}$ & None & Acceptable & Minimal & $\begin{array}{l}\text { Not available in clinic for } \\
\text { group treatment }\end{array}$ \\
\hline $\begin{array}{l}\text { Minimal to free for walking } \\
\text { and basic aerobic exercise }\end{array}$ & $\begin{array}{l}\text { Muscle aches and joint } \\
\text { pain (transient) }\end{array}$ & May not sustain & Major & Easily available \\
\hline $\begin{array}{l}\text { Minimal (may need initial } \\
\text { educational counseling from } \\
\text { dietitian or nutritionist) }\end{array}$ & $\begin{array}{l}\text { Headache and } \\
\text { gastrointestinal } \\
\text { discomfort (transient) }\end{array}$ & May not sustain & Major & Easily available \\
\hline Minimal & None & Acceptable & $\begin{array}{l}\text { No (except take } \\
\text { the pills) }\end{array}$ & ОTС \\
\hline Minimal & $\begin{array}{l}\text { Headache, heartburn, } \\
\text { nausea, vomiting }\end{array}$ & $\begin{array}{l}\text { Acceptable if not } \\
\text { experiencing side } \\
\text { effects }\end{array}$ & $\begin{array}{l}\text { No (except take } \\
\text { the pills) }\end{array}$ & ОТС \\
\hline Minimal & Acne and hirsutism & $\begin{array}{l}\text { Not acceptable by } \\
\text { most young females }\end{array}$ & $\begin{array}{l}\text { No (except take } \\
\text { the pills) }\end{array}$ & Prescription/OTC \\
\hline $\begin{array}{l}\text { Expensive even with health } \\
\text { insurance }\end{array}$ & $\begin{array}{l}\text { Headache, gastrointestinal } \\
\text { complaints, infection, } \\
\text { increased suicidal ideation, } \\
\text { and transient ischemic } \\
\text { attacks }\end{array}$ & $\begin{array}{l}\text { Acceptable by most } \\
\text { patients }\end{array}$ & $\begin{array}{l}\text { No (except take } \\
\text { the pills) }\end{array}$ & Required prescription \\
\hline $\begin{array}{l}\text { May not be covered by } \\
\text { health insurance; not } \\
\text { approved by FDA for its } \\
\text { use to treat SLE }\end{array}$ & $\begin{array}{l}\text { Erythema, pruritus, } \\
\text { hyperpigmentation, } \\
\text { and induction of } \\
\text { photodermatoses, } \\
\text { phototoxicity, and } \\
\text { photocarcinogenesis }\end{array}$ & $\begin{array}{l}\text { Acceptable if not } \\
\text { experiencing side } \\
\text { effects }\end{array}$ & No & $\begin{array}{l}\text { Not available in every major } \\
\text { lupus center }\end{array}$ \\
\hline $\begin{array}{l}\text { Not normally covered by } \\
\text { health insurance plan }\end{array}$ & $\begin{array}{l}\text { Dizziness, } \\
\text { lightheadedness, and } \\
\text { local bruising, pain during } \\
\text { needle insertion }\end{array}$ & $\begin{array}{l}\text { Acceptable if no fear } \\
\text { of needles }\end{array}$ & No & $\begin{array}{l}\text { Available in many areas, } \\
\text { efficacy may depend on the } \\
\text { expertise of the acupuncturist }\end{array}$ \\
\hline
\end{tabular}

low-to-moderate levels of evidence. Psychosocial interventions, dietary manipulation (low calorie or glycemic index diet), vitamin D supplementation, and acupuncture all had weak evidence. Finally, DHEA is not recommended due to lack of evidence for its efficacy.

SLE-related fatigue is a complex phenomenon and a broad array of factors is commonly associated with fatigue. Optimal fatigue management should, therefore, start with a comprehensive evaluation of the patient as relates to these factors. Ideally, treatment strategies should be tailored to the individual patient's physical and psychosocial health status, and their cultural background. Any comorbidities such as psychological distress, chronic pain, sleep disturbance, obesity, and hypovitaminosis $\mathrm{D}$ that are associated with fatigue should be addressed.

\section{Disclosure}

The authors report no conflicts of interest in this work.

\section{References}

1. Gualtierotti R, Biggioggero M, Penatti AE, Meroni PL. Updating on the pathogenesis of systemic lupus erythematosus. Autoimmun Rev. 2010; 10:3-7.

2. D'Cruz DP, Khamashta MA, Hughes GR. Systemic lupus erythematosus. Lancet. 2007;369:587-596.

3. Petri M, Genovese M, Engle E, Hochberg M. Definition, incidence, and clinical description of flare in systemic lupus erythematosus. A prospective cohort study. Arthritis Rheum. 1991;34:937-944.

4. Danchenko N, Satia JA, Anthony MS. Epidemiology of systemic lupus erythematosus: a comparison of worldwide disease burden. Lupus. 2006; 15:308-318.

5. Trager J, Ward MM. Mortality and causes of death in systemic lupus erythematosus. Curr Opin Rheumatol. 2001;13:345-351. 
6. Schmeding A, Schneider M. Fatigue, health-related quality of life and other patient-reported outcomes in systemic lupus erythematosus. Best Pract Res Clin Rheumatol. 2013;27:363-375.

7. Krupp LB, LaRocca NG, Muir J, Steinberg AD. A study of fatigue in systemic lupus erythematosus. J Rheumatol. 1990;17:1450-1452.

8. Ahn GE, Ramsey-Goldman R. Fatigue in systemic lupus erythematosus. Int J Clin Rheumatol. 2012;7:217-227.

9. Da Costa D, Dritsa M, Bernatsky S, et al. Dimensions of fatigue in systemic lupus erythematosus: relationship to disease status and behavioral and psychosocial factors. J Rheumatol. 2006;33:1282-1288.

10. Jump RL, Robinson ME, Armstrong AE, Barnes EV, Kilbourn KM, Richards HB. Fatigue in systemic lupus erythematosus: contributions of disease activity, pain, depression, and perceived social support. J Rheumatol. 2005;32:1699-1705.

11. Omdal R, Waterloo K, Koldingsnes W, Husby G, Mellgren SI. Fatigue in patients with systemic lupus erythematosus: the psychosocial aspects. J Rheumatol. 2003;30:283-287.

12. Mancuso CA, Perna M, Sargent AB, Salmon JE. Perceptions and measurements of physical activity in patients with systemic lupus erythematosus. Lupus. 2011;20:231-242.

13. Chaiamnuay S, Bertoli AM, Fernandez M, et al. The impact of increased body mass index on systemic lupus erythematosus: data from LUMINA, a multiethnic cohort (LUMINA XLVI) [corrected]. J Clin Rheumatol. 2007;13:128-133.

14. Oeser A, Chung CP, Asanuma Y, Avalos I, Stein CM. Obesity is an independent contributor to functional capacity and inflammation in systemic lupus erythematosus. Arthritis Rheum. 2005;52:3651-3659.

15. Tayer WG, Nicassio PM, Weisman MH, Schuman C, Daly J. Disease status predicts fatigue in systemic lupus erythematosus. J Rheumatol. 2001; 28:1999-2007.

16. Wysenbeek AJ, Leibovici L, Weinberger A, Guedj D. Fatigue in systemic lupus erythematosus. Prevalence and relation to disease expression. Br J Rheumatol. 1993;32:633-635.

17. Omdal R, Mellgren SI, Koldingsnes W, Jacobsen EA, Husby G. Fatigue in patients with systemic lupus erythematosus: lack of associations to serum cytokines, antiphospholipid antibodies, or other disease characteristics. J Rheumatol. 2002;29:482-486.

18. Wang B, Gladman DD, Urowitz MB. Fatigue in lupus is not correlated with disease activity. J Rheumatol. 1998;25:892-895

19. Pettersson S, Lovgren M, Eriksson LE, et al. An exploration of patientreported symptoms in systemic lupus erythematosus and the relationship to health-related quality of life. Scand J Rheumatol. 2012;41: 383-390.

20. Baker K, Pope J. Employment and work disability in systemic lupus erythematosus: a systematic review. Rheumatology (Oxford). 2009;48: 281-284.

21. Scofield L, Reinlib L, Alarcón GS, Cooper GS. Employment and disability issues in systemic lupus erythematosus: a review. Arthritis Rheum. 2008;59:1475-1479.

22. Bexelius C, Wachtmeister K, Skare P, Jönsson L, Vollenhoven RV. Drivers of cost and health-related quality of life in patients with systemic lupus erythematosus (SLE): a Swedish nationwide study based on patient reports. Lupus. 2013;22:793-801.

23. Danoff-Burg S, Friedberg F. Unmet needs of patients with systemic lupus erythematosus. Behav Med. 2009;35:5-13.

24. Moses N, Wiggers J, Nicholas C, Cockburn J. Prevalence and correlates of perceived unmet needs of people with systemic lupus erythematosus. Patient Educ Couns. 2005;57:30-38.

25. Moher D, Liberati A, Tetzlaff J, Altman DG; PRISMA Group. Reprint preferred reporting items for systematic reviews and meta-analyses: the PRISMA statement. Phys Ther. 2009;89:873-880.

26. Dobkin PL, Da Costa D, Fortin PR, et al. Living with lupus: a prospective pan-Canadian study. J Rheumatol. 2001;28:2442-2448.

27. Navarrete-Navarrete N, Peralta-Ramirez MI, Sabio-Sanchez JM, et al. Efficacy of cognitive behavioural therapy for the treatment of chronic stress in patients with lupus erythematosus: a randomized controlled trial. Psychother Psychosom. 2010;79:107-115.
28. Greco CM, Rudy TE, Manzi S. Effects of a stress-reduction program on psychological function, pain, and physical function of systemic lupus erythematosus patients: a randomized controlled trial. Arthritis Rheum. 2004;51:625-634.

29. Haupt M, Millen S, Janner M, Falagan D, Fischer-Betz R, Schneider M. Improvement of coping abilities in patients with systemic lupus erythematosus: a prospective study. Ann Rheum Dis. 2005;64: $1618-1623$.

30. Karlson EW, Liang MH, Eaton $\mathrm{H}$, et al. A randomized clinical trial of a psychoeducational intervention to improve outcomes in systemic lupus erythematosus. Arthritis Rheum. 2004;50:1832-1841.

31. Austin JS, Maisiak RS, Macrina DM, Heck LW. Health outcome improvements in patients with systemic lupus erythematosus using two telephone counseling interventions. Arthritis Care Res. 1996;9: 391-399.

32. Dobkin PL, Da Costa D, Joseph L, et al. Counterbalancing patient demands with evidence: results from a pan-Canadian randomized clinical trial of brief supportive-expressive group psychotherapy for women with systemic lupus erythematosus. Ann Behav Med. 2002;24:88-99.

33. Sohng KY. Effects of a self-management course for patients with systemic lupus erythematosus. J Adv Nurs. 2003;42:479-486.

34. Robb-Nicholson LC, Daltroy L, Eaton H, et al. Effects of aerobic conditioning in lupus fatigue: a pilot study. Br J Rheumatol. 1989;28: $500-505$.

35. Goligher EC, Pouchot J, Brant R, et al. Minimal clinically important difference for 7 measures of fatigue in patients with systemic lupus erythematosus. J Rheumatol. 2008;35:635-642.

36. Zhang J, Wei W, Wang CM. Effects of psychological interventions for patients with systemic lupus erythematosus: a systematic review and meta-analysis. Lupus. 2012;21:1077-1087.

37. De Carvalho MR, Sato EI, Tebexreni AS, Heidecher RT, Schenkman S, Neto TL. Effects of supervised cardiovascular training program on exercise tolerance, aerobic capacity, and quality of life in patients with systemic lupus erythematosus. Arthritis Rheum. 2005;53: 838-844.

38. Clarke-Jenssen AC, Fredriksen PM, Lilleby V, Mengshoel AM. Effects of supervised aerobic exercise in patients with systemic lupus erythematosus: a pilot study. Arthritis Rheum. 2005;53:308-312.

39. Yuen HK, Holthaus K, Kamen DL, Sword DO, Breland HL. Using Wii Fit to reduce fatigue among African American women with systemic lupus erythematosus: a pilot study. Lupus. 2011;20: 1293-1299.

40. Daltroy LH, Robb-Nicholson C, Iversen MD, Wright EA, Liang MH. Effectiveness of minimally supervised home aerobic training in patients with systemic rheumatic disease. Br J Rheumatol. 1995; 34:1064-1069.

41. Ramsey-Goldman R, Schilling EM, Dunlop D, et al. A pilot study on the effects of exercise in patients with systemic lupus erythematosus. Arthritis Care Res. 2000;13:262-269.

42. Tench CM, McCarthy J, McCurdie I, White PD, D'Cruz DP. Fatigue in systemic lupus erythematosus: a randomized controlled trial of exercise. Rheumatology (Oxford). 2003;42:1050-1054.

43. Krupp LB, LaRocca NG, Muir-Nash J, Steinberg AD. The fatigue severity scale. Application to patients with multiple sclerosis and systemic lupus erythematosus. Arch Neurol. 1989;46:1121-1123.

44. McNair DM, Lorr M, Droppleman LF. POMS Manual: Profile of Mood States. San Diego, CA, USA: Educational and Industrial Testing Service; 1992

45. Katz P, Gregorich S, Yazdany J, et al. Obesity and its measurement in a community-based sample of women with systemic lupus erythematosus. Arthritis Care Res (Hoboken). 2011;63:261-268.

46. Katz P, Julian L, Tonner MC, et al. Physical activity, obesity, and cognitive impairment among women with systemic lupus erythematosus. Arthritis Care Res (Hoboken). 2012;64:502-510.

47. Katz P, Yazdany J, Julian L, et al. Impact of obesity on functioning among women with systemic lupus erythematosus. Arthritis Care Res (Hoboken). 2011;63:1357-1364. 
48. Davies RJ, Lomer MC, Yeo SI, Avloniti K, Sangle SR, D’Cruz DP. Weight loss and improvements in fatigue in systemic lupus erythematosus: a controlled trial of a low glycaemic index diet versus a calorie restricted diet in patients treated with corticosteroids. Lupus. 2012;21:649-655.

49. Breslin LC, Magee PJ, Wallace JM, McSorley EM. An evaluation of vitamin D status in individuals with systemic lupus erythematosus. Proc Nutr Soc. 2011;70:399-407.

50. Ruiz-Irastorza G, Gordo S, Olivares N, Egurbide MV, Aguirre C. Changes in vitamin D levels in patients with systemic lupus erythematosus: effects on fatigue, disease activity, and damage. Arthritis Care Res (Hoboken). 2010;62:1160-1165.

51. Fragoso TS, Dantas AT, Marques CD, et al. 25-Hydroxyivitamin D3 levels in patients with systemic lupus erythematosus and its association with clinical parameters and laboratory tests. Rev Bras Reumatol. 2012;52:60-65.

52. Stockton KA, Kandiah DA, Paratz JD, Bennell KL. Fatigue, muscle strength and vitamin D status in women with systemic lupus erythematosus compared with healthy controls. Lupus. 2012;21:271-278.

53. Thudi A, Yin S, Wandstrat AE, Li QZ, Olsen NJ. Vitamin D levels and disease status in Texas patients with systemic lupus erythematosus. Am J Med Sci. 2008;335:99-104.

54. Ruiz-Irastorza G, Egurbide MV, Olivares N, Martinez-Berriotxoa A, Aguirre C. Vitamin D deficiency in systemic lupus erythematosus: prevalence, predictors and clinical consequences. Rheumatology. 2008;47:920-923.

55. Perl A. Oxidative stress in the pathology and treatment of systemic lupus erythematosus. Nat Rev Rheumatol. 2013;9:674-686.

56. Shah D, Sah S, Wanchu A, Wu MX, Bhatnagar A. Altered redox state and apoptosis in the pathogenesis of systemic lupus erythematosus. Immunobiology. 2013;218:620-627.

57. Lai ZW, Hanczko R, Bonilla E, et al. N-acetylcysteine reduces disease activity by blocking mammalian target of rapamycin in $\mathrm{T}$ cells from systemic lupus erythematosus patients: a randomized, double-blind placebo-controlled trial. Arthritis Rheum. 2012;64:2937-2946.

58. Michielsen HJ, De Vries J, Van Heck GL. Psychometric qualities of a brief self-rated fatigue measure: The Fatigue Assessment Scale. J Psychosom Res. 2003;54:345-352.

59. de Kleijn WP, De Vries J, Wijnen PA, Drent M. Minimal (clinically) important differences for the Fatigue Assessment Scale in sarcoidosis. Respir Med. 2011;105:1388-1395.

60. Crosbie D, Black C, McIntyre L, Royle PL, Thomas S. Dehydroepiandrosterone for systemic lupus erythematosus. Cochrane Database Syst Rev. 2007;4:CD005114.

61. Derksen RH. Dehydroepiandrosterone (DHEA) and systemic lupus erythematosus. Semin Arthritis Rheum. 1998;27:335-347.

62. Overman CL, Hartkamp A, Bossema ER, et al. Fatigue in patients with systemic lupus erythematosus: the role of dehydroepiandrosterone sulphate. Lupus. 2012;21:1515-1521.

63. van Vollenhoven RF, Engleman EG, McGuire JL. An open study of dehydroepiandrosterone in systemic lupus erythematosus. Arthritis Rheum. 1994;37:1305-1310.

64. van Vollenhoven RF, Park JL, Genovese MC, West JP, McGuire JL. A double-blind, placebo-controlled, clinical trial of dehydroepiandrosterone in severe systemic lupus erythematosus. Lupus. 1999;8:181-187.

65. Chang DM, Lan JL, Lin HY, Luo SF. Dehydroepiandrosterone treatment of women with mild-to-moderate systemic lupus erythematosus: a multicenter randomized, double-blind, placebo-controlled trial. Arthritis Rheum. 2002;46:2924-2927.

66. Nordmark G, Bengtsson C, Larsson A, Karlsson FA, Sturfelt G, Rönnblom L. Effects of dehydroepiandrosterone supplement on healthrelated quality of life in glucocorticoid treated female patients with systemic lupus erythematosus. Autoimmunity. 2005;38:531-540.

67. Hartkamp A, Geenen R, Godaert GL, Bijl M, Bijlsma JW, Derksen RH. Effects of dehydroepiandrosterone on fatigue and well-being in women with quiescent systemic lupus erythematosus: a randomised controlled trial. Ann Rheum Dis. 2010;69:1144-1147.
68. Petri MA, Lahita RG, Van Vollenhoven RF, et al. Effects of prasterone on corticosteroid requirements of women with systemic lupus erythematosus: a double-blind, randomized, placebo-controlled trial. Arthritis Rheum. 2002;46:1820-1829.

69. Petri MA, Mease PJ, Merrill JT, et al. Effects of prasterone on disease activity and symptoms in women with active systemic lupus erythematosus. Arthritis Rheum. 2004;50:2858-2868.

70. Ding HJ, Gordon C. New biologic therapy for systemic lupus erythematosus. Curr Opin Pharmacol. 2013;13:405-412.

71. Townsend MJ, Monroe JG, Chan AC. B-cell targeted therapies in human autoimmune diseases: an updated perspective. Immunol Rev. 2010;237:264-283.

72. Petri M, Stohl W, Chatham W, et al. Association of plasma B lymphocyte stimulator levels and disease activity in systemic lupus erythematosus. Arthritis Rheum. 2008;58:2453-2459.

73. Furie R, Petri M, Zamani O, et al; BLISS-76 Study Group. A phase III, randomized, placebo-controlled study of belimumab, a monoclonal antibody that inhibits B lymphocyte stimulator, in patients with systemic lupus erythematosus. Arthritis Rheum. 2011;63: 3918-3930.

74. Navarra SV, Guzman RM, Gallacher AE, et al; BLISS-52 Study Group. Efficacy and safety of belimumab in patients with active systemic lupus erythematosus: a randomised, placebo-controlled, phase 3 trial. Lancet. 2011;377:721-731.

75. Strand V, Levy RA, Cervera R, et al; BLISS-52 and -76 Study Groups. Improvements in health-related quality of life with belimumab, a B-lymphocyte stimulator-specific inhibitor, in patients with autoantibody-positive systemic lupus erythematosus from the randomised controlled BLISS trials. Ann Rheum Dis. 2014;73:838-844.

76. van Vollenhoven RF, Petri MA, Cervera R, et al. Belimumab in the treatment of systemic lupus erythematosus: high disease activity predictors of response. Ann Rheum Dis. 2012;71:1343-1349.

77. Merrill JT, Ginzler EM, Wallace DJ, et al; LBSL02/99 Study Group. Long-term safety profile of belimumab plus standard therapy in patients with systemic lupus erythematosus. Arthritis Rheum. 2012;64:3364-3373.

78. Manzi S, Sanchez-Guerrero J, Merrill JT, et al; BLISS-52 and BLISS-76 Study Groups. Effects of belimumab, a B lymphocyte stimulatorspecific inhibitor, on disease activity across multiple organ domains in patients with systemic lupus erythematosus: combined results from two phase III trials. Ann Rheum Dis. 2012;71:1833-1838.

79. Wallace DJ, Navarra S, Petri MA, et al; BLISS-52 and -76, and LBSL02 Study Groups. Safety profile of belimumab: pooled data from placebo-controlled phase 2 and 3 studies in patients with systemic lupus erythematosus. Lupus. 2013;22:144-154.

80. McGrath H, Jr. Ultraviolet-A1 irradiation decreases clinical disease activity and autoantibodies in patients with systemic lupus erythematosus. Clin Exp Rheumatol. 1994;12:129-135.

81. Polderman MC, Huizinga TW, Le Cessie S, et al. UVA-1 cold light treatment of SLE: a double blind, placebo controlled crossover trial Ann Rheum Dis. 2001;60:112-115.

82. Samsa G, Edelman D, Rothman ML, Williams GR, Lipscomb J, Matchar D. Determining clinically important differences in health status measures: a general approach with illustration to the Health Utilities Index Mark II. Pharmacoeconomics. 1999;15:141-155.

83. Polderman MC, le Cessie S, Huizinga TW, Pavel S. Efficacy of UVA-1 cold light as an adjuvant therapy for systemic lupus erythematosus. Rheumatology (Oxford). 2004;43:1402-1404.

84. Gambichler T, Terras S, Kreuter A. Treatment regimens, protocols, dosage, and indications for UVA1 phototherapy: facts and controversies. Clin Dermatol. 2013;31:438-454.

85. Wang T, Zhang Q, Xue X, Yeung A. A systematic review of acupuncture and moxibustion treatment for chronic fatigue syndrome in China. Am J Chin Med. 2008;36:1-24.

86. Greco CM, Kao AH, Maksimowicz-McKinnon K, et al. Acupuncture for systemic lupus erythematosus: a pilot RCT feasibility and safety study. Lupus. 2008;17:1108-1116. 
87. Ware JE Jr, Sherbourne CD. The MOS 36-item short-form health survey (SF-36). I. Conceptual framework and item selection. Med Care. 1992;30:473-483.

88. Chou CT. Alternative therapies: what role do they have in the management of lupus? Lupus. 2010;19:1425-1429.

89. Abou-Raya A, Abou-Raya S, Helmii M. The effect of vitamin D supplementation on inflammatory and hemostatic markers and disease activity in patients with systemic lupus erythematosus: a randomized placebo-controlled trial. J Rheumatol. 2013;40:265-272.
90. Strand V, Petri M, Kalunian K, et al. Epratuzumab for patients with moderate to severe flaring SLE: health-related quality of life outcomes and corticosteroid use in the randomized controlled ALLEVIATE trials and extension study SL0006. Rheumatology (Oxford). 2014;53:502-511.

91. Danoff-Burg S, Agee JD, Romanoff NR, et al. Benefit finding and expressive writing in adults with lupus or rheumatoid arthritis. Psychol Health. 2006;21:651-665.

\section{Publish your work in this journal}

Therapeutics and Clinical Risk Management is an international, peerreviewed journal of clinical therapeutics and risk management, focusing on concise rapid reporting of clinical studies in all therapeutic areas, outcomes, safety, and programs for the effective, safe, and sustained use of medicines. This journal is indexed on PubMed Central, CAS,
EMBase, Scopus and the Elsevier Bibliographic databases. The manuscript management system is completely online and includes a very quick and fair peer-review system, which is all easy to use. Visit http://www.dovepress.com/testimonials.php to read real quotes from published authors.

Submit your manuscript here: http://www.dovepress.com/therapeutics-and-clinical-risk-management-journal 